\title{
LA MAREA EN LA NAVEGACIÓ COMERCIAL MEDITERRÀNIA (SEGLES XIV-XVI)
}

\author{
ARCADI GaRcia I SANZ \\ Universitat Jaume I (Castello)
}

\begin{abstract}
SUMARI
1. El cicle diari del curs de la marea. - 2. El cicle mensual del curs de la marea.- 3. L'establiment de port.
\end{abstract}

En la historiografia de l'art de navegar no és habitual relacionar els mètodes nàutics amb rutes determinades del comerç maŕtim, tot $i$ que potser molts d'aquests metodes tenen aquest origen.

Ara examinarem un exemple que sembla molt clar, d'aquesta relacio, que és el de la cronografia nàutica de la marea, la qual sembla haver tingut l'origen en la ruta atlantica del comerç marítim de les ciutats mediterrànies del segle XIV.

És un fenomen natural ben conegut que la major oscil.lació de l'aigua a la mar, en que consisteix la marea, es produeix als oceans, on la massa líquida és major. A les mars tancades aquesta diferència és molt menor, fins a arribar a fer-se imperceptible en alguns llocs.

També és un fenomen natural ben conegut que l'acció gravitatoria preponderant, en la determinació de la marea, és la de la Lluna i que, durant els equinoccis, aquesta acció gravitatoria combinada amb la del Sol fa major l'oscil.lació del nivell de l'aigua a la mar. Aixı, a la badia de Montsaint-Michel, a la costa bretona del Nord-Est, aquesta oscil.lació és de 15 metres, i a l'estret de Magallanes, a l'extrem meridional d'America, la mateixa oscil.lació és de 18 metres. 
Aquestes característiques naturals de la marea fan que aquesta sigui més intensa a les costes atlantiques d'Europa que no pas a les mediterrànies. Un indret característic de marea intensa és la costa de Bretanya, on genera, a vegades, durant la marea viva, un corrent mari, denominat ras o raz, que s'afegeix al creixent de la mar. En el ras de Sein, al golf de Morbihan, aquest corrent arriba als 10 o 12 nusos de velocitat'.

Aquesta diferent importància que tenia la marea per a la navegacio a les costes atlàntiques $i$ a les mediterrànies, es tradueix clarament en el dret maritim comercial dels segles XIII i XIV, propi d'unes costes i unes altres. Així, els Róles d'Oléron, que són la col.lecció juŕ́dico-marítima més representativa d'aquests segles a l'Europa atlàntica, en les regles de balisament de les àncores, quan el vaixell fondeja, distingueixen la situació de la baixamar (où il i a poi d'ewe "on hi ha poca aigua") del cas de la plenamar (au plein) ${ }^{2}$. En canvi, el Llibre del Consolat de Mar, que és la col.lecció jurf́dico-maŕtima més característica dels mateixos segles a l'Europa mediterrània, ni al capitol 246, que tracta dels senyals de les àncores, ni als capitols 200 a 203, que contenen les regles del fondejament del vaixell, no fa cap referència a la marea ${ }^{3}$.

Sembla, doncs, força clar que, el darrer quart del segle XIII, quan els vaixells mediterranis arribaren en els seus viatges comercials a les costes bretones, angleses i flamenques, es trobaren amb una dificultat nova, que no hi havia a les costes mediterrànies, on el fenomen natural de la marea no suposava una dificultat greu per a la navegació.

Contràriament, pero, al que hom podria pensar d'antuvi, es dóna el fet, aparentment paradoxal, que les fonts historiques més antigues conegudes a la costa atlàntica d'Europa sobre la cronografia nàutica de la marea són més tardanes que les mediterrànies, ja que la més antiga que en sabem és al Routier de la mer, de Pierre Garcie-Ferrande, datat el 1483-1484 i, la seva primera edicio, el $1487^{4}$. En canvi, a les ciutats marítimes medi-

\footnotetext{
'Enrique MARTINEZ JIMÉNEZ i Ricardo RUIZ, 8.v. marea, dins Enciclopedia general del mar, dirigida per José MARTINEZ-HIDALGO, Barcelona, 1968, V, col. 877-918.

${ }^{2}$ Róles d'Oléron, edic. de Karl-Friedrich KRIEGER. Ursprung und Würzeln der Rôles d'Oléron, Colonia, 1970, pp. 122-145, capítol 16.

${ }^{3}$ Uibre del Consolat de Mar, edic. de Germà CoLon i Arcadi GARCIA, Barcelona, 19811987, I, pp. 188-195 i II, pp. 31-33.

${ }^{4}$ Michel MoLLAT, La vie quotidienne des gens de mer en Atlantique (IXe-XVIe siecle), Paris, 1983, pp. 183-184, mab refencia a D. W. WATERS, The Rutters of the Sea. The Sailing Directions of Pierre Garcie, New Haven-Londres, 1967.
} 
terrànies, d'aquestes fonts historiques, n'hi ha del segle XIV i de la primera meitat del XV.

Tot seguit ho veurem, a l'exàmen que en farem, amb base heurística en les fonts que semblen més expressives, durant l'epoca de vigencia del calendari julià, que és l'anterior a la reforma gregoriana d'aquest, de l'any 1582.

\section{El CICLE DIARI DEL CURS DE LA MAREA}

Diàriament, la marea fa quatre fases, dues marees altes o plenamars i dues baixes o baixamars, les quals alternen, de manera que després d'una plenamar ve una baixamar i viceversa. La plenamar ve determinada pels passos de la Lluna pel meridià del lloc i per l'antimeridia, i la marea baixa la determina el pas del mateix astre pels límits de longitud de la seva sortida i de la seva posta.

Com que aquests quatre moments, en realitat, son conseqüencia del moviment de rotació de la Terra, la successió d'aquestes quatre fases de la marea és diària, que el dia natural no és altra cosa que el període de temps que hi ha entre dos passos consecutius del Sol, en el seu moviment aparent, per un mateix medirià o, cosa que és igual, el temps que triga la Terra a fer una volta completa sobre el seu eix de rotació.

Cal dir, pero, que la Lluna, en aquest seu moviment aparent, ha d'esmerçar més temps que el Sol per situar-se, altra vegada, en relació a la Terra, en la mateixa posició de pas pel meridià d'un lloc, i aixo fa que el dia solar i el luna no siguin iguals.

Aquesta diferencia entre el dia solar i el lunar era valorada en 4/5 d'una hora solar equinoccial, motiu pel qual el pas de la Lluna pel meridià d'un lloc s'esdevenia 48 minuts més tard per dia que el pas del Sol pel mateix meridià. I aixo mateix, aplicat a la marea, significava que, en comput d'hores solars equinoccials, cada fase de la marea diària es retardava cada dia de 48 minuts d'hora, en relació a la mateixa fase del dia abans. 
En la representacio angular de les hores equinoccials a l'astrolabi, cada una d'aquestes equivalia a $15^{\circ 5} \mathrm{i}$, per tant, el valor angular d'aquests 48 minuts d'hora era de $12^{\circ}$ en la circumferencia zodiacal de l'astrolabi.

Com que el comput amb aquests $12^{\circ}$ resultava enutjos, perque $15 \mathrm{i}$ 12 no són divisibles entre si, fou ideat un altre metode de representacio cronogràfica, que era només aproximatiu, pero que resultava familiar per a la gent de mar i permetia operar amb números enters i amb hores solars equinoccials.

Aquest mètode era el de la rosa nàutica, usada com a instrument cronogràfic, en substitució de la corona zodiacal de l'astrolabi. En aquesta rosa, igual que a la rosa del compas, els $360^{\circ}$ de la circumferencia eren dividits en 32 quartes de vent, d' $11^{\circ} 15^{\prime}$ cadascuna, 8 de les quals fan els $90^{\circ}$ que hi ha de diferencia angular entre els quatre vents cardinals: cada vent principal en fa $45^{\circ}$ i el mig vent en ta $22^{\circ} 30^{\prime}$, tal como ho mostra gràficament la figura següent:

\section{Rosa ndutica}
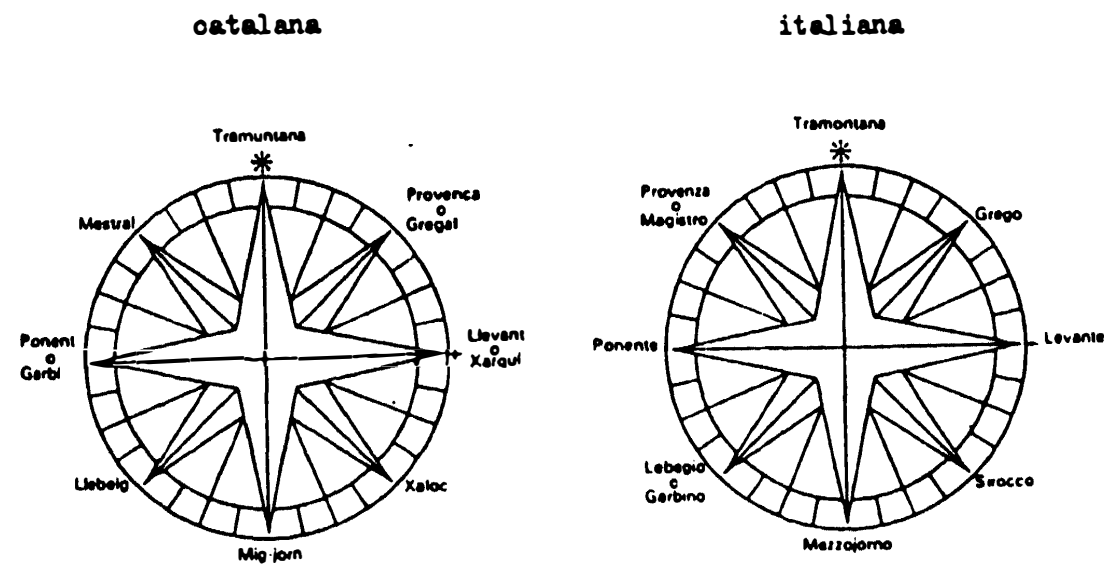

Perque el còmput cronogràfic a la rosa resultés exacte, només calia atribuir al retard diari del pas de la Lluna pel meridia i, consegüentment, al retard diari de la marea un valor cronologic de 45 minuts d'hora, en comptes dels 480 , dit d'una altra manera, fer l'esmentat retard de $3 / 4$ d'hora,

\footnotetext{
'Arcadi Garcin i Francesc de Rocafiguera, Cronografia topica del calendari julid, Castello, 1993, pp. 93-94.
} 
en comptes dels $4 / 5$ en que el valorava l'Astrologia tradicional, puix que $3 / 4$ d'hora $\times 32$ quartes $=24$ hores.

D'aquesta manera, el comput horari del dia lunar era molt facil i, a més, era possible fer-lo amb hores solars equinoccials, amb les següents equivalencies cronologiques dels valors angulars.

Una quarta equivalia a $3 / 4$ d'hora, mig vent equivalia a 1 hora $\mathrm{i}$ mitja, un vent principal a 3 hores i un vent cardinal, que són dos de principals, a 6 hores. En conseqüencia, la distància angular entre dues fases consecutives de la marea diaria era de dos vents $\left(=8\right.$ quartes $\left.=90^{\circ}\right)$, les dues plenamars de cada dia eren a la rosa en vents oposats, les dues baixamars, igualment, $i$ el retard diari de la marea a la rosa era d'una quarta $(=3 / 4$ d'hora).

Aquest metode permetia tambe relacionar la posició azimutal del Sol amb la de la Lluna, puix que cada dia aquesta s'allunyava d'aquell una quarta $i$, per tant, en tot moment, la distància azimutal d'un astre a l'altre era de tantes quartes de vent com dies tenia l'edat de la Lluna.

En l'expressió angular de les fases de la marea diaria a la rosa dels vents, coneixem dues formes diferents, l'una veneciana i l'altra catalana 0 , en general, occidental.

La forma veneciana, continguda en diversos manuscrits de la primera meitat del segle $\mathrm{XV}^{6}$, posava el començament del primer creixent de la marea a Llevant de la rosa, amb la qual cosa el segon quedava a Ponent i l'inici de les baixamars, a Tramuntana i Migjorn.

\footnotetext{
${ }^{6}$ Biblioteca Nazionale Centrale, de Florència, ms. ilta. c. XIX, c. 7, intitulat "Fabrica di galere" (vers l'any 1410), fol. $122 \mathrm{v}$. "Ragione del fluxo et refluxo de le aque marine.- Sapi che quan la Luna sie in Levante, l'acqua comenza a crescere in fin che la Luna sie in Ostro et sie andando hore 6, per che la Luna si ha cerchado 2 venti. Da poi che la Luna sie in Ostro in fin ch.ela.ndara in Ponente, l'acqua andara zoxo et serra.ndata hore 6. Da poi ch.ela sera in Ponente in fin ch.ela sera in Tramontana, l'acqua cresce et sie andata hore 6. Da poi ch.cla c in Tramontana in fin ch.ela va in Levante, l'acqua va zoxo et sie andata hore 6".

Es trobe també aquesta forma de representació cronografica del curs diari de la marea al ms. Cotton Titus A. 26, fol. 17 v., de la British Library, de Londres, titulat factíciament "Note di architettura navale", obra de Zoria da Modone, datada vers l'any 1445.

Devem i agraìm la comunicació d'aunbdós al Dr. Laureà CARBONELI I RELAT, el qual transcriví en la seva tesi doctoral titulada La marina en el Mediterráneo del siglo XV. llegida a la Facultat de Geografia i Història de la Universitat de Barcelona, el 17 de juny de 1991.
} 
La forma occidental o catalana, continguda dins el Mapamundi d'Abraham Cresques', de l'any 1375, i en diverses obres nàutiques castellanes i occidentals, dels segles $\mathrm{XV}$ i XVI ${ }^{8}$, posava la primera plenamar a Gregal, amb la qual cosa la segona quedava a Llebeig i les baixmars, a Mestral i Xaloc.

Tot i i que, aparentment, entre l'una forma i l'altra hi ha una diferència angular d'un vent a la rosa, que són tres hores, en realitat es tracta de la mateixa forma de representació angular, car la diferència és només de la radix del comput, el qual la forma veneciana inicia a Llevant de la rosa cronogràfica $i$, que en canvi, la forma catalana o occidental estableix a Gregal la mateixa rosa.

La finalitat d'aquesta darrera forma de reperesntació cronogràfica sembla que era la de fer coincidir, d'una manera ostensible, el $S$ amb les 12 del migdia, que a l'hemisferi Nord és la posició aparent del Sol a l'horitzo en aquesta hora, cosa que permetia fer el comput amb les hores equinoccials del dia.

Per aconseguir aquest resultat, emperd, la rosa cronogràfica no podia estar en el pla de l'horitzo, perque en aquesta posicio les hores que marcava eren les temporals o desiguals, les quals només eren iguals els dies dels equinoccis i, la resta de l'any, de banda de primavera i d'estiu, les diürnes eren més llargues que les nocturnes $i$, de banda de tardor i d'hivern, al contrari.

Calia, doncs, variar el pla de la rosa per fer-lo coincidir amb el pla de l'equador, on totes les hores són iguals. Ho diu molt clarament Pedro Medina', segons el qual "estos vientos (els de la rosa) no se han de ymagi-

\footnotetext{
'CRESQUes, Mapamundi, edic. de Georges GROSJEAN. Mapamundi. The catalan atlas of the year 1375, Dietikon-Zurich, 1978, p. 43 (transcripció revisada): "devets saber que, con la Luna és per Grech, les mares comensen a muntar, tro que la Luna és per Exeloch, que són .VIII. quartes de vent e són. VI. hores. Item, con la Luna és per Axeloch, les ay gües comensen a muntar, tro que la Luna és per Lebeg, e són. VIII. quartes de vent, que són .VI. hores. Item, con la Luns és per Lebeg, les aygües comensan a muntat, tant tro que la Luna es per Mestre, e són. VIII. quartes de vent, que són. VI. hores. Item, con la Luna és per Mestre, les aygües comensan a muntar, tant tro que la Luna és per Grech. E axí aquestes mares del ras Sant Maen tro en Boqua d'Aver fan aquest cors nit e jom, dues marees muntants i qrexents e dues marees muntants e baxants, e quascuna .VI. hores, si que quatre veguades. VI. veln e són.XXIIII. hores".

"Martín CORTEs, Breve compendio de la Sphera y de la Arte de Navegar, Sevilla, 1551; Pedro de MEDINA, Arre de Navegar, Valladolid, 1545, i Regimiento de navegación, Sevilla, 1563, reedic. anast., Valencia, 1993.

'MEDINA, Regimiento de navegación, abans citat, fols. 53-53 v.
} 
nar en el orizonte, donde la aguja los enseña, mas hanse de ymaginar sobre el Norte puesto que el ángulo debaxo del orizonte", que és tant com dir que la rosa cal imaginar-la en un pla paral.lel al de l'equador.

Amb aquesta disposicio, el volt del Sol a la rosa marcava les hores solars equinoccials: al $N$ les 12 de la nit, al $N E$ les 3, a l' $E$ les 6 , al $S E$ les 9 , al $S$ les 12 del migdia, i aix les hores restants als altres vents de la rosa.

Acaba de fer patent aquesta funció cronogràfica de la rosa dels vents una tabulació de l'hora solar de la plenamar diaria, que porta el mateix Medina, feta per als 30 dies del mes lunar, d'acord amb aquest mètode de la rosa dels vents.

La tabulació es la següent ${ }^{10}$ :

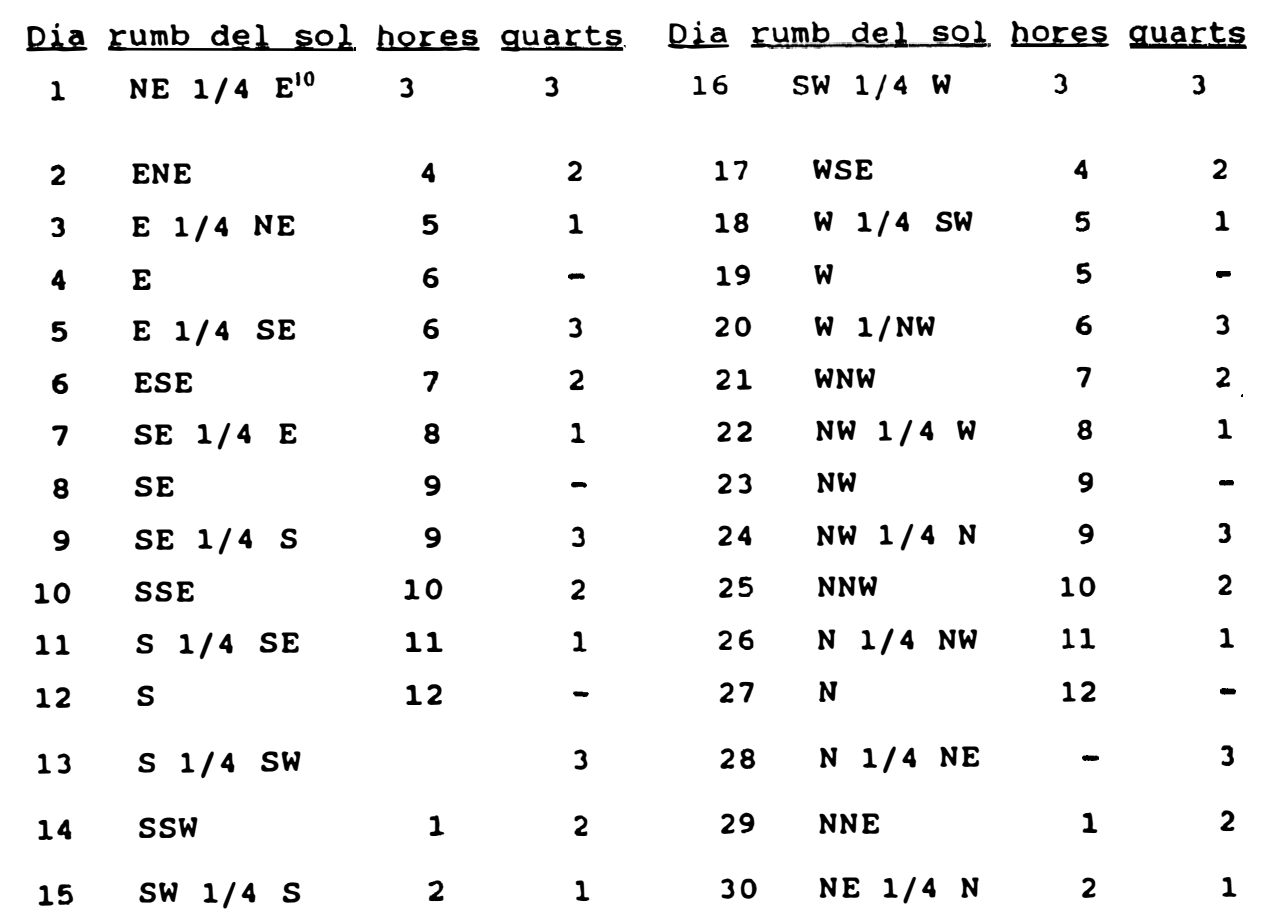

\footnotetext{
${ }^{10}$ Tot i que MEDINA, Regimiento, f. 54, hi posa clarament Norte quarta al Nordeste, aquest rumb és errat, tal coin ho mostra l'hora de les 3 i $3 / 4$ i ho mostren també els rumbs següents dels dies posteriors, a la mateixa taula, i cal llegir, per tant, Nordeste quarta al Leste, tal com ho esmenem. Vegcu també les observacions sobre aquest mètode cronografic que fa Salvador GARCla FRANCO, Historia del arte y ciencia de navegar, II, Madrid, 1947, p. 165.
} 
En realitat, aquesta tabulació horària conté dues taules iguals juxtaposades i simetriques en llur posició a la rosa: l'una del dia 1 al 15 i l'altra del 16 al 30 del mes lunar. Són els dies del "punt" de la marea viva, que després examinarem, $\mathrm{i}$ les hores de la plenamar, les quals a la rosa dels vents resulten oposades.

Tot i que a la taula no hi ha expressats els vents $N E$ i $S W$, que són per a la Lluna els de la plenamar, precisament, cal dir que en els dies si que hi són comptats perquè, dels dies 15 i 30 fins a l'endemà de cada un, el retard de la plenamar no hi és comptat per 3/4 d'hora sinó per 1 hora $\mathrm{i}$ mitja, que és el retard corresponent a dos dies o dues quartes de vent a la rosa.

Aquesta irregularitat és deguda al fet que els vents de la rosa són 32 , pero els dies del mes lunar són només $30 \mathrm{i}$, per tant, hi sobraven 2 vents, els quals hi son expressats només d'aquesta manera implícita.

Les hores que s'hi expressen son hores solars equinoccials, representades pel rumb del Sol a la rosa dels vents equatorial, i el seu comput és fet pel mètode astrologic, que després explicarem, i per dies completi.

La radix d'aquest comput és posada a les hores de plenamar dels dies de marea viva, quan la Lluna és al $N E$ o al $S W$ de la rosa i el Sol una quarta de vent més enllà, girant ambdós astres a la rosa en el sentit dels rellotges mecànics actuals. El dia 1, quan la Lluna és al $N E$ i el Sol al $N E$ $1 / 4 E$, l'hora solar que li pertoca és la propia de la posició del Sol en aquest rumb de la rosa, que és la de les 3 hores i 3 quarts després de la mitjanit; i el dia 16 , quan la Lluna és al $S W$ i el Sol al $S W 1 / 4 W$, el comput és el mateix, segons el qual l'hora solar és la de les 3 hores i 3 quarts després del migdia. Ambdues hores resulten oposades -a distancia cronologica de 12 hores- perque els rumbs a la rosa també ho són.

El caràcter més geomètric que experimental d'aquesta tabulació, que ara ens ocupa, resulta evident, motiu pel qual en la seva aplicació pràctica freturava de correccio, perquè, de fet, no pas tots els novilunis s'escauen a la mateixa hora solar, ni menys encara a les 3 hores i 3 quarts després de la mitjanit, tal com ho posa la taula. Per aixo, si hom disposava d'un llunari on s'expressés l'hora del noviluni, la diferencia d'hores que hi hagués amb l'hora tabulada, bé de més o bé de menys, calia sumar-la o restar-la d'aquella.

El mètode, finalment, feia necessari -és clar- el coneixement de l'edat de la Lluna, per saber quin era el dia del mes lunar. Pero aixd també 
tenia els seus metodes propis, no solament a la Cronografia topica, sinó també a la nàutica, tal com ho examinarem seguidament.

\section{El CiCle MENSUAL DEL CURS DE LA MAREA}

Ja hem dit abans que, en la determinació del curs de la marea, la intenstitat gravitatoria preponderant és la de la Lluna i, per aixo, la cadència cronologica de la marea segueix sensiblement el curs d'aquest astre.

Mensualment, la Lluna segueix el curs de les fases o quarts (lluna nova, creixent, plena i minvant) i cada cicle complet forma un mes lunar, el qual en els mesos senars és de 30 dies i en els parells de 29, de manera que l'any lunar té 12 mesos, igual que el solar, però només 354 dies. La diferència entre l'un any i l'altre és, doncs, d'11 dies i rep el nom d'epac$\mathrm{ta}^{11}$.

La marea, mensualment, segueix aquest curs de les fases de la Lluna, de tal manera que quan aquesta, la Terra $i$ el Sol es troben en línia recta (sizigia), bé en conjució o bé en oposició entre la Lluna i el Sol, cosa que s'esdevé en noviluni i en el pleneluni, les accions gravitatories del Sol i de la Lluna se sumen i donen lloc al màxim d'elevació del nivell de l'aigua, que és denominat marea viva o aighes vives. En canvi, quan la Lluna $i$ el Sol es troben en posicio de quadratura -formant angle recte amb el vèrtex a la Terra- cosa que s'esdevé en el quart creixent $i$ en el minvant, les accions gravitatories del Sol i de la Lluna es contraresten i donen lloc al mínim d'elevació del nivell de l'aigua, que és denominat marea morta o aigules mortes ${ }^{12}$.

"GARCIA I Rocafiguera, Cronografia topica (cit. supra, n. 5), p. 188.

${ }^{12}$ MARTINEZ I RUIZ, art. marea, cit, supra n. 1. 
L'esquema següent ho mostra d'una manera gràfica:

\section{Curs mensual de la marea}

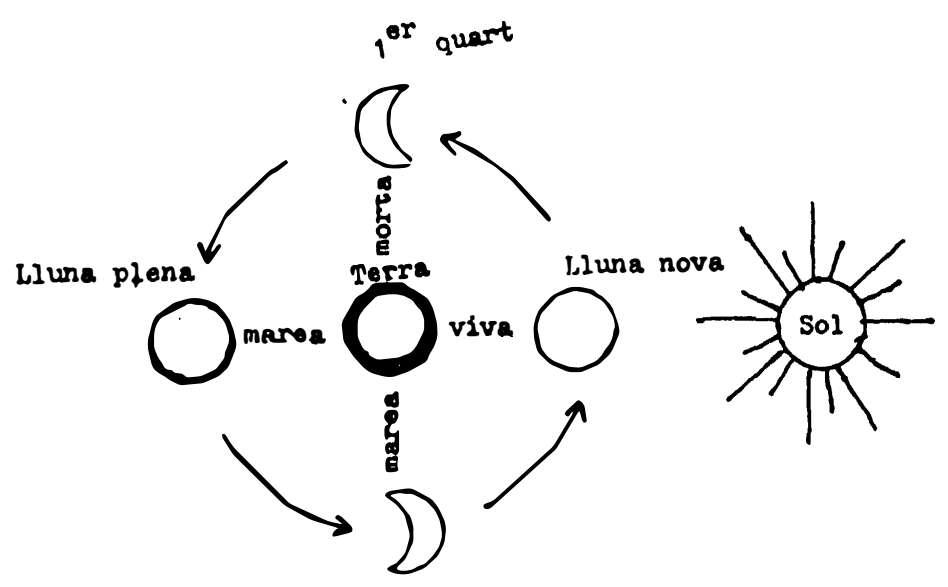

La representació cronogràfica d'aquest curs de la marea era molt simple: com que els novilunis eren assenyalats al calendari per mitjà del numerus aureus de l'any en què s'esdevenia el dia solar assenyalat, eren facils d'establir el noviluni de cada mes i els quarts restants de la Lluna d'aquell mes, per tal de precisar els dies de marea viva i els de marea morta.

Cal fer, pero, algunes puntualitzacions sobre els mètodes cronogràfics tòpics del calendari lunar, per tal d'identificar els susats per la cronografia nàutica per a l'establiment dels novilunis, i per tal de fer entenedora la clara diversitat, que s'observa d'antuvi, en l'escaiença solar dels mateixos novilunis a la cronografia de la marea.

Tal com ho exposàrem en una altra ocasio ${ }^{13}$, l'establiment dels novilunis en el Calendari Julià es basava en el cicle metonic segons el qual, de cada 19 anys solars, es repetien els novilunis els mateixos dies del calendari solar. Aixd donava lloc a un cicle cronologic de 19 anys, en el qual aquests eren numerats ordinalment de l' 1 fins al 19 per mitjà del que hom en deia el numerus aureus. El dia assenyalat al calendari solar amb aquest numerus aureus era el del noviluni dels anys d'aquell numerus aureus, el

${ }^{13}$ Garcia I Rocafigutera, Cronografia tòpica, pp. 219-220. 
qual era el dia 1 del mes lunar. Els dies restants del mateix mes lunar eren comptats successivament per l'ordre dels números naturals fins al darrer del mes, que era o bé el 29 o bé el 30 . Aquest còmput era denominat de l'edat de la Lluna.

Cal dir, pero, que en el Calendari Julià, com a conseqëència de la precessio dels novilunis, de cada 312'5 anys el noviluni real s'anticipava d'un dia, en relació amb el que hi havia assenyalat al calendari, motiu pel qual, a partir del segle XIV, són coneguts exemplars del calendari lunar amb la sèrie dels novilunis anticipada, en relació a la del calendari lunar tradicional. I no solament aixo, sino que alguns d'aquests exemplars precisen no solament el dia del noviluni, sinó també l'hora i el minut.

Parió del cicle del numerus aureus era el cicle de l'epacta, que era format per la progressio aritmetica determinada per la diferencia d'11 dies, que hi havia entre l'any solar i el lunar, la qual s'anava acumulant d'any en any. Quan la dita progressio superava els 30 dies, que són un mes lunar complet, hom la simplificava, amb subtracció de 30 unitats, afegint un mes al calendari lunar (embolisme).

Cal dir, pero, que de l'epacta metonica són coneguts tres cicles diferents, el primer dels quals quals és el romà, el segon el vulgar i el tercer el que seguia el calendari ${ }^{14}$.

A la taula següent hi ha la correlació entre el cicle del numerus aureus i aquestes tres formes del cicle de l'epacta.

Formes del cicle de l'epacta

\begin{tabular}{|c|c|c|c|c|c|c|c|c|c|c|}
\hline Numerus eureys & I & II & III I & IV & $\mathbf{v}$ & VI & VII & VII & & $x$ \\
\hline forma romana & 11 & 22 & 3 & 14 & 25 & 6 & 17 & 28 & & 9 \\
\hline forma vulgar & 29 & 11 & 22 & 3 & 14 & 25 & 6 & & 7 & 28 \\
\hline forma del calendarl & 18 & 29 & 11 & 22 & 3 & 14 & 25 & & 6 & 17 \\
\hline umerus aureus & $x I$ & $X I I$ & XIII & $x$ & IV & xv & XVI & XVII & XVII & II \\
\hline forma romana & 1 & 12 & 23 & & 4 & 15 & 26 & 7 & & 18 \\
\hline forma vulgar & 20 & 1 & 12 & & 23 & 4 & 15 & 26 & & 7 \\
\hline orma del & & 20 & 1 & & 12 & 23 & 4 & 25 & & 26 \\
\hline
\end{tabular}

${ }^{14}$ Ibidein, p. 191. 
En la Cronografia tòpica del Calendari Julià, el mètode més simple d'obtenció de la data solar del noviluni de cada mes era el dels regulars lunars, que són uns números que, sumats a l'epacta propia de l'any objecte de comput, donen per a cada mes solar la datació lunar del dia ${ }^{15}$. Són diferents -és clarper a cada forma del cicle de l'epacta. Per a la forma roma$\mathrm{na}^{16}$, que és la que ara ens interessa, aquests regulars lunars són els següents:

\section{Regulars lunars}

gener fobrer marg abril maig funy jullol agost setembre octubro novbro.desbre.

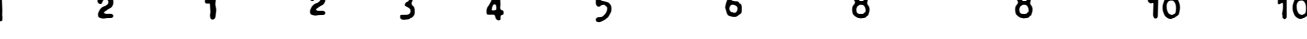

Per a l'establiment del curs mensual de la marea, en la Cronografia nàutica del Calendari Julià els mètodes tòpics, que acabem de resumir, eren emprats tot sovint d'una manera simplificativa i especial, motiu pel qual val la pena d'examinar-los amb una mica d'atenció.

El cicle del numerus aureus era seguit per la Cronografia nàutica d'una manera molt pura, sense simplificacions ni irregularitats. L'única singularitat que s'hi troba, a vegades, és la de la manera d'obtenir-lo, la qual en la Cronografia topica consistia a obtenir el residu de la divisió $\mathrm{N}+1$, on $N$ és l'any de Crist ${ }^{17}$. La Cronografia nàutica, en canvi, comptava aquesta constant anual del comput cronologic a partir d'un any determinat, de numerus aureus conegut, bo i afegint-hi una unitat cada any, fins al 19, que recomençava el comput.

Aixl, Abraham Cresques ${ }^{18}$ el compta a partir de l'any 1375, que té el numerus aureus 8, i Pedro de Medina ${ }^{19}$ el compta a partir de l'any

\footnotetext{
15 Ibidem, pp. 141-142.

${ }^{16}$ Les 8 unitats de diferència, que hi ha entre els regulars lunars comuns $i$ aquests de la forma romana del cicle de l'epacta, són pels 8 dies de diferència que hi ha al calendari entre el noviluni de l'any del numer'us aureus $\mathrm{I} i \mathrm{el}$ del numerus aureus III, que inicien, respectivament, el cómput de l'any lunar en l'una forna i l'altra del cicle de l'epacta, tal corn es pot somprovar al calendari luna (Ibid., pp. 165-166).

${ }^{17}$ Bbidem, p. 220.

${ }^{18}$ CRESQUes, Mapamundi (cd. cit. supia n. 7), p. 38.

${ }^{19}$ MFDINA, Regimiento (cit. supia n. 8), fol. $51 \mathrm{v}$.
} 
1501, que té el numerus aureus 1. Quan hi havia més d'un cicle i, per tant, els anys comptats passaven de 19, s'hi restaven aquests, una vegada o més, per mantenir el numerus aureus entre 1 i 19.

En el comput de l'edat de la Lluna, la Cronografia nàutica seguia amb molta fidelitat el comput astrologic i el feia per dies complet ${ }^{20}$, és a dir, comptant els dies sencers i de migdia a migdia, de tal manera que el dia assenyalat al llunari o calendari lunar s'acabava al migdia d'aquella mateixa data solar. Pedro de Medina posa l'exemple del noviluni d'un did 2 del mes solar, que s'escau en dilluns, i precisa que aquell dia s'acabava el mateix dilluns a migdia i, si es tractava d'un llunari, que determinava els novilunis per dies $i$ hores, les hores eren després d'aquell migdia ${ }^{21} i$, per tant del dia lunar següent.

Aquest sembla que era un metode d'ús general en els llunaris, perque Bernat de Granollachs ${ }^{22}$ (c. 1485) també l'explica. És per aixd que pot servir com a criteri general d'interpretació dels calendaris lunars, tant nàutics com topics.

Aquest criteri és important perque, del segle XIV ençà, tal com ho hem dit abans, són relativament corrents els calendaris lunars que anticipen els novilunis, en relació a llur escaiença en el tradicional, $i$ molts ho fan assenyalant-hi, no solament el dia, sinó també l'hora i el minut.

Aquesta anticipació era conseqüència de la precessió dels novilunis, abans esmentada, d'acord amb la qual en el Calendari Julia, de cada 312 anys i sis mesos, el noviluni s'anticipava d'1 dia.

A la Cronografia nàutica aquesta anticipació dels novilunis és molt patent, perque té valors diversos, segons l'epoca de composicio de cada obra. És per aixo que sembla haver estat aquesta Cronografia l'estímul permanent que donà lloc a aquestes actualitzacions del Calendari lunar Julia, que són les que portaren a la reforma gregoriana d'aquest, l'any 1582.

Aquest ús nautic dels cicles del numerus aureus i de l'epacta fa també explicable, en aquests calendaris lunars corregits, la persistència de les 235 llunacions tradicionals del cicle metonic ${ }^{23}$, puix que, mantenint

\footnotetext{
${ }^{20}$ GaRCia I Rocafiguera, Cronografia topica (cit. supra n. 5), pp. 114-115.

${ }^{21}$ MEDINA, Regimiento, fol. 45.

${ }^{2}$ Josep Chavas i Antoni RocA, El "Lunari" de Bemat de Granollachs. Alguns aspectes de la histdria de l'astronomia a la Catalunya del Quatrecents, Barcelona, 1985, p. 111.

${ }^{23}$ GarCia I Rocafiguera, Cronografia topica (cit. supra n. 5), p. 227.
} 
aquest cicle, no calia variar ni el cicle del numerus aureus ni el de l'epacta, encara que variés la datació solar dels novilunis.

Per tal que hom es faci càrrec d'aquesta variació de la datació solar del novilunis, a la taula següent mostrem juxtaposades les datacions solars dels novilunis de cada mes de l'any del numerus aureus 5, tal com són al calendari lunar tradicional ${ }^{24}$, del qual coneixem exemples documentats des del segle $X$, al calendari de Cresques ${ }^{25}$, de l'any 1375 , al llunari de Granollachs $^{26}$, del 1485, i al de Medina ${ }^{27}$, del 1563.

\section{Variació de la datació solar del novilunis}

Any de "numerus aureus" 5

Tradic.

$$
\text { Cresques }
$$

Granollachs

Medina

mesos dies

dies hores minuts

dies hores minuts

dies

\begin{tabular}{ll} 
gener & 9 \\
febrer & 7 \\
març & 9 \\
abril & 7 \\
maig & 7 \\
juny & 5 \\
juliol & 5 \\
\multicolumn{1}{|l}{} & - \\
agost & 3 \\
setembre & 2 \\
octubre & 2 \\
\multicolumn{1}{c}{ " } & 31 \\
novembre & 30 \\
desembre & 29
\end{tabular}

$\begin{array}{rrr}6 & 0 & 58 \\ 4 & 11 & 46 \\ 5 & 20 & 42 \\ 4 & 5 & 17 \\ 3 & 13 & 19 \\ 2 & -- & -- \\ 1 & -- & -- \\ 30 & 21 & 56 \\ 29 & 13 & 8 \\ 28 & 7 & 4 \\ 28 & 0 & 28 \\ -- & - & -- \\ 26 & 8 & 27 \\ 26 & 11 & 14\end{array}$

$\begin{array}{rrr}5 & 13 & 55 \\ 4 & 5 & 22 \\ 5 & 18 & -- \\ 4 & 3 & 55 \\ 3 & 11 & 49 \\ 1 & 18 & 35 \\ 1 & 1 & 28 \\ 30 & 9 & 31 \\ 28 & 19 & 47 \\ 27 & 8 & 58 \\ 27 & 1 & 6 \\ -- & - & - \\ 25 & 19 & 45 \\ 25 & 15 & 15\end{array}$

4

3

4

2

2

1

-

29

28

27

27

--

${ }^{24}$ Ibldem, pp. 165-166.

${ }^{25} \mathrm{Jbid}$., pp. 229-240.

${ }^{26}$ Cit. supra $\mathrm{n} .22$.

${ }^{27}$ MEDINA, Regimiento, fol. $49 \mathrm{v}$. 
Al llunari de Medina hi ha l'anomalia que, de l'1 de juny al 29 de juliol solars, no hi ha cap noviluni. Si hom compara aquest llunari amb els altres tres de la taula, troba que, efectivament, al de Medina hi manca el 13e noviluni d'aquell any. Sembla doncs, que cal llegir-hi un altre noviluni el 29 de juny.

A la Cronografia nàutica, el cicle de l'epacta era seguit d'una manera especial, $i$ fins $i$ tot manipulada, tant en el cicle mateix com en els regulars lunars, motiu pel qual val la pena d'examinar-los amb una mica d'atenció.

La primera irregularitat que hom hi pot pbservar és que, dels tres cicles de l'epacta, que abans hem exposat, la Cronografía nàutica no en segueix el de l'epacta vulgar, sino el de la romana, tal com es pot comprovar a la correlació que segueix, on hi ha la del numerus aureus amb l'epacta, tal com l'estableix Medina ${ }^{28}$.

Correlació del "nuınerus aureus" aimb l'epacta, segons Medina

\begin{tabular}{|c|c|c|c|c|c|c|c|c|c|c|c|}
\hline Numerus & aureus & I & I I & I I I & IV & VI & VII & VIII & IX & $x$ & \\
\hline Epacta & & 11 & 22 & 3 & 1425 & 6 & 17 & 28 & 92 & 20 & \\
\hline Numerus & aureus & $X I$ & $X I I$ & XIII & XIV & $x V$ & XVI & XVII & XVII & I I & $X I X$ \\
\hline Epacta & & 1 & 12 & 23 & 4 & 15 & 26 & 7 & & 18 & 29 \\
\hline
\end{tabular}

Tot i que aquest autor, de l'epacta d'aquest cicle, en diu concurriente, la sèrie numerica precedent no és del concurrent del cicle solar ${ }^{29}$, sino de l'epacta minor o epacta lunar del cicle metonic. La discrepancia d'aquests números epactals amb els del cicle de l'epacta vulgar, que era cosa corrent acl, sembla haver estat el motiu que indur Medina adonar-li aquest nom.

\footnotetext{
${ }^{28}$ Ibidem, fol. 52.

${ }^{29}$ Garcia I Rocafiguera, Cronografia topica, pp. 133-134.
} 
No contradiu l'ús d'aquest cicle romà de l'epacta el fet que algun manuscrit venecià del segle $\mathrm{XV}^{30}$ atribueixi a l'any del numerus aureus I l'epacta 10, i no pas 1'11; aixó és degut a la circumstància que, si hom feia el saltus Lunae, en el qual l'epacta és $12^{31}$, l'any del numerus aureus III, tal com el fa el cicle epactal del calendari, en comptes de fer-lo l'any del numerus aureus XIX, que ès el que pertoca en aquest cicle romà, l'any del numerus aureus I resultava d'epacta 10, car $29+11-30=10$, i el del numerus aureus III, en canvi, quan hom feia el saltus Lunae, la sèrie dels números epactals tornava a coincidir amb la romana, perque $21+12-30=3$.

A Venècia historicament és explicable l'ús d'aquest cicle romà de l'epacta, pero als països hispànics, fins ara, no l'hem vist mai usat a la Cronografia topica. El nom de concurriente, que li dóna Medina, ja indica la seva raresa entre nosaltres i fa pensar en una procedencia veneciana, 0 almenys italiana, d'aquest mètode.

Un altre indici cronogràfic de procedencia veneciana d'aquest mètode, que sembla molt expressiu, és el dels regulars lunars, com a mitjà per a l'establiment dels dies de noviluni en el calendari solar i per al comput de l'edat de la Lluna.

Els regulars lunars usats per la Cronografia nàutica són -és clar- els propis del cicle romà de l'epacta, que acabem d'exposar. Pero la seva serie no coincideix exactament amb la que hem mostrat abans, sinó que presenta dues particularitats molt característiques.

La primera d'aquestes particularitats és que, d'acord amb l'estil venecià del canvi de l'any, muda aquest el dia 1 de març i, per tant, la sèrie dels regulars és ordenada des de març fins al febrer següent, amb la qual cosa, segons el estil actual del canvi d'any l' 1 de gener, aquest mes i el de febrer són els de l'any immediatament següent.

La segona particularitat és que aquests regulars lunars de la Cronografia nàutica només coincideixen amb els de la Cronografia topica fins al mes d'agost, i que en els mesos posteriors segueixen la numeracio correlativa fins al 12, tal com ho mostra la taula següent:

\footnotetext{
${ }^{30}$ Piero de VERSI, "Raxon de marineri". Biblioteca Nazionale Centrale, de Venècia, ms. ital., cl. IV, cod. 5379, fols. 3.4 r., de l'any 1445. Devem i agraïm la comunicació al Dr. Laurea Carbonell, el qual el transcrivi en la seva tesis doctoral, cit. supra n. 6.

"Garcia i Rocafiguera, Cronografia topica, (cit. supra) n. 8), fols. 153-154 i 190-196.
} 
Regulars lunars de la Cronografia nàutica

març. abr. maig. juny. jul. ag. set. oct. nov. des. gen. feb.

\begin{tabular}{lllllllllllll}
\hline 1 & 2 & 3 & 4 & 5 & 6 & 7 & 8 & 9 & 10 & 11 & 12
\end{tabular}

És evident que aquesta sèrie dels regulars lunars, els mesos de setembre i novembre discrepa de la sèrie de la Cronografia topica en 1 unitat. Pel gener i febrer no hi ha discrepancia, perque les 10 unitats de diferencia que hi ha entre un sèrie i l'altra són les que s'arrosseguen de desembre, que en aquest còmput és del mateix any. La inexactitud que aixo suposava era, doncs, poca.

La finalitat d'aquesta manipulació de la sèrie dels regulars lunars era la d'obtenir una regla simple per trobar la datacio solar del noviluni de qualsevol mes sense necessitat de calendari.

En efecte,la suma de l'epacta propia de l'any i el regular propi del mes, ja hem dit abans que donava la datacio lunar del dia 1 del mes solar. En conseqüencia, restant aquesta suma dels 29 o 30 dies del mes lunar, la diferencia donava la datació solar del noviluni. Pero, com que en aquesta forma nàutica de la sèrie dels regulars lunars cada un d'aquests equivalia al número de mesos transcorreguts des de l' 1 de març, el substrahend d'aquesta resta era la suma de l'epacta de l'any i el número de mesos transcorreguts des de l'l de març fins al mes que era objecte de comput. Aixl, per exemple, la datació solar del noviluni de juliol de l'any d'epacta 6 era el dia 19 d'aquest mes solar, puix que $30-(6+5)=19$.

Totes dues particularitats de la Cronografia nàutica, tal com les acabem d'exposar, es troben al manuscrit venecià del segle $\mathrm{XV}$, abans citat $^{32}$, i al Regimiento de navegación, de Pedro de Medina, que prescriu el canvi de l'epacta anual, precisament el dia 1 de març, i assenyala el noviluni de juliol de l'any d'epacta 6, el dia 19 d'aquest mes solar ${ }^{33}$.

Per als regulars solars -que són diferents dels lunars- la primera de les dites particularitats, que és la del comput a partir de l'l de març, es troba també en algunes obres cronogràfiques catalanes del segle $\mathrm{XIV}^{34}$,

\footnotetext{
${ }^{32}$ Versi. "Raxon de marineri" (cit. supra n. 30), fols. 5 v. -6 r.

${ }^{33}$ MEDINA, Regimiento (cit. supra, n. 8), fols. 52 i 49 v.

${ }^{34}$ Garcia i Rocafiguera, Cronografia topica, p. 137.
} 
però la de la sèrie dels regulars lunars sembla específica de la cronografia nàutica.

Un cop establerta la datació solar del noviluni, el comput de l'edat de la Lluna tenia poques dificultats. Es podia fer per comput manual o digital o bé per mitjà del calendari. D'una manera directa el seu còmput es podia fer també per mitjà dels mateixos regulars lunars, mètode en el qual, per trobar l'edat de la Lluna d'un dia qualsevol del mes solar, només calia afegir a la suma del regular i l'epacta els dies transcorreguts fins al que era objecte de comput, puix que el regular ja donava la datació lunar del dia 1 del mes solar. El mètode és el mateix de la Cronografia topica ${ }^{35}$.

Coneguda la datació solar del noviluni i, per tant, les dels dies restants del mes lunar, el comput de la marea seguia el curs de les fases de la Lluna, que abans hem exposat, començant per les aiglles vives del dia 1 del mes lunar, que era el del noviluni.

D'aquestes fases de marea viva i de marea morta, en coneixem tres distribucions mensuals, les quals, si bé coincideixen totes tres amb el cicle de les fases de la Lluna, fan una distribució diferent de les aigües vives i de les aigües mortes dintre dels 30 dies del mes lunar.

El manuscrit venecià de Zorzi da Modone ${ }^{36}$, del 1445, diu que en els 30 dies del mes lunar hi ha dues marees vives (aque forte) i dues de mortes (aque fele), de les quals cada marea viva dura 10 dies i cada marea morta en dura 5. Efectivament, $(10+5) \times 2=30$.

Un altre manuscrit venecia dels primers anys del segle $X^{37}$, que tracta de les galeres venecianes de la ruta comercial de Flandes ${ }^{38}$ i que, per tant sembla més atent a les marees de la costa atlàntica d'Europa, fa la següent distribució de les fases de la marea entre els 30 dies del mes lunar:

En tot el mes lunar aquest manuscrit posa dos "punts" d'aigua, que són el del dia 1, que és el del noviluni i el gran ponto, i un altre ponto de $a q u a$, el dia del pleniluni (tondo de la Lluna). Evidentment, tant l'un punt com l'altre són els de marea viva. Entre aquests dos "punts" de la marea,

\footnotetext{
${ }^{35}$ Bbldein, p. 142.

${ }^{36}$ ZORZI DA MODONE, Note di archisettura navale, ms. cit. supra, n. 6, fol.18 r.

${ }^{37}$ Fabrica di galere, cit. supra n. 6, fol. 122 v.

${ }^{38}$ Sobre aquesta ruta comercial, ef. Francisco SEVILLANO COLOM, De Venecia a Flandes (via Mallorca y Portugal, siglo XIV), "Boletín de la Sociedad Arqueológica Luliana", 33 (1968), pp. 1-33, i Frederic C. LANE, Venetian merchant Galleys, 1300-1334: private and commural operation, "Speculum", 38 (1963), pp. 179-205.
} 
després del primer, fa durar les aigües vives del dia 1 al 5 del mes lunar. Del dia 5 al 9, hi posa la marea morta, amb dos dies (del 5 al 7) en que les aigües es mouen poc, $i$ uns altres dos dies (del 7 al 9), que són els maxims de marea morta. Després del segon "punt", aquest manuscrit posa la marea viva del tondo de la Lluna (dia 15$)^{39}$ fins al dia $19 \mathrm{i}$, del 19 al 23, la marea morta, amb dos dies (del 19 al 21) en que les aigües es mouen poc, $i$ uns altres dos en que posa la major marea morta. Del dia 23 del mes lunar al 30, aquest manuscrit no en diu res, però és evident que hi prossuposa el creixent de la marea, que dura fins al gran ponto del dia 1 del mes lunar següent.

L'altra distribució que coneixem, del curs mensual de la marea entre els 30 dies del mes lunar, és la hispànica, de la qual hi ha testimoniatges historics dels segles XIV al XVI ${ }^{40}$.

En aquesta distribucio hi ha també els dos "punts" d'aigua (cabeça de agua, segons Medina), el dia 1 del mes lunar i el dia 15, que són també el del noviluni i el del pleniluni, els quals són els de marea viva, i el primer el del major creixent d'aquesta; del dia 1 del mes lunar fins al 8 , segons aquesta distribucio, minva la marea $i$, aquest, darrer, ni creix ni minva; del dia 9 fins al 15, torna a créixer la mar; del 16 al 22 minva, una altra vegada, i del 23 al 30 torna a créixer fins al "punt" del dia 1 del mes lunar següent.

Aquests dos "punts" d'aigua, del dia 1 del mes lunar i del dia 15, eren representats a la rosa dels vents cronogràfica per la seva plenamar, la qual, per a la Lluna, el dia 1 del mes lunar quedava al $N E$ i el dia 15 al $S W$, tal com ho hem vist abans, quan hem parlat de l'hora de la plenamar en el cicle diari de la marea, $i$ tal com ho veurem potser millor encara, dintre d'un moment, quan parlarem dels retards locals de la marea.

\footnotetext{
${ }^{39}$ El calendari lunar tradicional, els mesos de 30 dies, ssenyalava el pleniluni el dia 14 del mes lunar, (GARCIA i ROCAFIGUERA, Cronografia topica, pp. 199-200). L'assenyalament d'questa fase el dia 15, tal com ho fa la Cronografia nautica, significa, doncs, una variació de la distribució tradicional de les fases de la Lluna.

${ }^{40}$ Sembla implícita en l'obra de CRESQUES i l'exposa molt clarament MEDINA, Regimiento, (cit. supra, n. 8), fols. 52v.-53.
} 


\section{L'ESTABLIMENT DE PORT}

Fins ara hem examinat el comput del curs normal de la marea i els mètodes cronogràfics de la seva representació, d'acord amb el Calendari Julià. Pero la realitat és que molt sovint hi ha diferència temporal entre l'hora real de la plenamr d'un lloc i l'hora calculada o tabulada per a la mateixa plenamar, i que aquesta diferència temporal no és igual, moltes vegades, ni tan sols en llocs propers d'una mateixa costa.

Aquest retard-o anticipació- de la plenamar és la que actualment s'anomena establiment de port, el qual, almenys en principi, és singular per a cada lloc. Els actuals es publiquen als almanacs nàutics $i$ als anuaris de marees.

Diu Abraham Cresques -que escrivia el segle XIV-que les marees fan el mateix curs en el creixent i minvant de la mar, del ras de Saint Merrin (ras Sant Main) fins a l'estret dels Dardanels (Boca d'Aver), si bé no son iguals a tot arreu ${ }^{41}$.

Aquesta extensa zona maritima, que va de l'extrem sud occidental de la Gran Bretanya fins a l'extrem oriental de la mar Mediterrània, és, sens dubte, la zona maritima de la qual Cresques -que era mallorqui- tenia experiència, bé directa o bé indirecta, per referències obtingudes de la gent de mar.

De tota aquesta extensa zona maritima, durant el segle XIV, les rutes comercials més navegades per italians $i$ catalans eren les de la mar Mediterrània i la de Flandes i d'Anglaterra ${ }^{42}$. Les primeres no tenien dificultats especials de navegació per raó de la marea, perque aquesta a la mar Mediterrània és poc intensa. Però a la ruta de Flandes i Anglaterra, que vorejava la costa atlàntica d'Europa, les marees son intenses i, per tant, suposaven una dificultat afegida a la navegació, sobretot al Canal de la Mànega (Canal de Flandes), per la proximitat de les costes i pels accidents topogràfics que hi ha en aquestes.

\footnotetext{
${ }^{41}$ Cresques, Mapamundi, edic. cit. supra n. 7, p. 43. GrosJeAn, en aquesta edició, identificà erradament el ras Sant Mein amb la Pointe de Saint-Mathieu, i la Boca d'Aver amb la badia de Le Havre, cosa amb la qual dislocà greument l'àmbit geogràjic expressat per CRESQUes. Per a la localització d'aquest darrer topónim, ef. Antoni RUBió i LlUCH, Diplomatari de l'Orient catald, Barcelona, 1947, p. 757.

${ }^{42}$ Richar W. UNGER, The Ship in the Medieval Economy. 600-1600, Montreal, 1980, pp. $175-200$.
} 
Aquest sembla el motiu pel qual el mateix Cresques dóna l'establiment de port de 14 llocs d'aquest canal, uns de la costa continental i uns altres de la costa anglesa.

Aquest establiment de port l'expressa Cresques pel metode cronogràfic de la rosa dels vents, que acabem d'examinar, i ho fa d'una manera gràfica, per mitjà d'un cercle pintat blau amb ones estilitzades, dividit en els 8 vents principals i aquests, en migs vents, on assenyala amb una $P$ la posició de la plenamar a la rosa $i$ amb una $B$, la baixamar, després d'haver advertit expressament que la norma de la posicio de la Lluna a la plenamar és al $N E$ (Grec) i al $S W$ (Llebeig) i la de la baixamar, al $N W$ (Mestre) i al SE (Vent ford), tal com abans ho hem explicat.

Aquest mateix metode de la rosa dels vents, per establir el retard de la marea, es troba també en el manuscrit venecià de Piero da Versi ${ }^{43}$, de l'any 1445 , bé que expressat per escrit i no pas gràficament. Aquest manuscrit dóna l'establiment de port dels llocs més característics de tota la costa atlantica de la ruta veneciana de Flandes, i no tan sols els del Canal de la Mànega, tal com ho fa Cresques; pero els que dóna aquest hi són tots $i$, per tant, se'n pot fer la comparació sense gran dificultat.

Cresques diu expressament que la zona marítima, d'on registra l'establiment de port, és la que va del Portland Bill (Mont de Gibetaria), a Anglaterra, fins a la Pointe de Ponmarch (Stoch de Pomarch), a la Bretanya. Els llocs extrems d'una riba i l'altra del Canal, d'on registra l'establiment de port, son, a la costa anglesa, Portland a l' $W$ i Sandwich a l' $E$, i a la costa continental, la Baie de la Seine al $N$ i l'illa de Sein al $S^{44}$.

Tant l'un autor com l'altre mesuren el temps de la variació de la plenamar dels dies de marea viva en els seus valors angulars a la rosa dels vents cronogràfica, en la qual la dita plenamar és posada al rumb que pertoca a l'hora que es produeix, de tal manera que aquesta variacio temporal la representa la diferencia angular que hi ha entre la norma de la plenamar amb la Lluna, bé al $N E$ o bé al $S W$, i la posició angular que ocupa en aquesta rosa de l'establiment del port.

\footnotetext{
${ }^{43}$ Piero DE VERSI, Raxon de marineri, ms. cit. supra n. 30, fols. 58 r. -61 r.

${ }^{4}$ Grosjean, a la seva edició del Mapamundi de Cresques (cit. supra n. 7), no va transcriure el cercle expressiu de l'establiment de port, el qual cal consultar directament al facsínil de la mateixa edició i, a mes, a l p. 38, identificà erradament el topònim Mont de Gibetaria amb el penyal de Gibraltar, cosa amb la qual altera substancialment l'ambit geografic expressat per Cresques.
} 
En el quadre de la p. 615, donem juxtaposats els valors angulars a la rosa dels vents que dónen, per a cada port, Abraham Cresques i Piero da Versi. Per tal d'identificar-ne els llocs, hi expressem el toponim actual de cada lloc, quan el coneixem, i els que donen aquests autors.

La primera observació que hom pot fer, en aquest quadre, és la gran similitud que hi ha en els valors de la variació horaria de la plenamar, entre Cresques i Versi, la majoria dels quals són els mateixos en l'un autor i l'altre. Les diferencies d'una quarta de vent no semblen significatives, perque Cresques fa la valoracio angular per migs vents $i$, en canvi, Versi la fa per quartes de vent, motiu pel qual la diferència de l'un autor a l'altre pot ésser deguda només a la manera d'expressar la fracció als valors angulars de la rosa.

En realitat, les úniques diferencies importants entre l'un autor $\mathrm{i}$ l'altre són de l'illa de Guernsey, que és de 2 quartes, i la de Sandwich, que és de 4 quartes a la plenamar i 2 a la baixamar. Aquesta irregularitat, que és a la rosa de Cresques, fa pensar en una possible errada.

Aquesta coincidencia entre Cresques i Versi es dóna també en el metode cronogràtic, car tots dos autors donen l'establiment de port per la posició de la Lluna a la rosa dels vents cronogràfica, i no pas per la posició del Sol, tot i que Cresques mateix dóna la regla per reduir l'una posició a l'altra ${ }^{45}$, tal com abans l'hem explicada.

Aquestes coincidencies plantegen el problema historic de l'origen del mètode de la rosa dels vents cronografica per a l'establiment del curs de la marea, sobre el qual hem fet abans algunes observacions particulars $\mathrm{i}$ que cal que ara examinem en el seu conjunt.

En aquesta cronografia nàutica de la marea, ja hem observat abans una procedencia italiana del cicle epectal romà i dels regulars lunars, dels quals fa ús, $\mathrm{i}$ hem observat igualment una influencia especificament veneciana de la serrie d'aquests, en fer-hi el canvi d'any precisament el dia 1 de març, d'acord amb l'estil cronografic venecià.

Aquesta procedencia italiana del metode de la rosa dels vents cronogràfica sembla refermada pel cercle que fa Cresques, per a l'establiment

\footnotetext{
${ }^{45}$ CRESQUES, Mapamundi, edic. cit. supra n. 7, p. 43: "Vós devets saber de la Luna quantes hores aura, cor lo comte devets saber, e per quasqun jom una quarta; donchs si la Luna ha .VIIII. joms, serà luny del Sol .VIII. quartes de vent; donchs si lo Sol és per Ponent, la Luna serà. VIII. quartes de vent luny e serà per Migjom, donchs podets entendre que les aigües munten e qurexen. E per aytants joms con la Luna aurd, aytantes quartes de vent ne serà luny del Sol".
} 
de port a les costes del Canal, el qual té les inicials dels noms italians dels 8 vents principals i no pas les inicials dels noms catalans dels mateixos vents, cosa deguda, probablement, al model que utilitzà aquest cartograf.

Altrament, Cresques només registra l'establiment de port de llocs de la Canal de Flandes i Piero da Versi, d'questes marees i de les restants de la costa atlantica d'Europa, diu queste sono le aque e le maie de Fiandria, la que se truova, la Luna e piena e bassa, per li porti e de fuora $i$ chanali. I aixd fa pensar que l'origen del mètode cronogràfic, que ara ens ocupa, es troba en la navegació comercial veneciana del segle XIV a la ruta de Flandes.

Les primeres referències dels vaixells mediterranis a Flandes són d'unes galeres genoveses, documentades allà, els anys 1277-1278 ${ }^{46}$. De mallorquines, n'hi ha de documentades a Londres el $1281 \mathrm{i}$ el $1304^{47}$.

El primer viatge documentat de galeres venecianes a Flandes és de l'any 1315 , quan el feren dues 0 tres galeres d'armadors particulars ${ }^{\mathbf{8}}$.

Cal dir, pero, que la forma més característica del comerç venecià amb Flandes i Anglaterra eren les mudue, organitzades oficialment amb vaixells públics prestats a armadors particulars. La primera ho fou l'any $1317-1318^{49}$. L'any 1332 , el sistema de préstec fou variat pel de subhasta, pero, a causa de l'estat de guerra permanent a la mar del Nord i al Canal de Flandes, l'any 1337 la mudua veneciana de Flandes fou suspesa i no tornà a reprendre fins l'any 1376 . És a partir d'aleshores quan es mantingué amb una certa regularitat o permanencia fins l'any 1532 , que cessà del tot $^{\text {so }}$.

Abraham Cresques, en qui ja hem observat aquestes influencies italianes, era mallorqur i escrivia l'any $1375 \mathrm{i}$, per tant, els models que utilitzava havien de ser anteriors. Pero, com que la mudua veneciana era suspesa de 1337 a 1376, sembla que aquests models havien d'haver estat

\footnotetext{
${ }^{46}$ Archibald R. LEWIS, Northern European Sea Power and the Strits of Gibraltar, 10311350, "Order and Innovation in the Middle Ages. Essays in Honor of Joseph R. Strayer", Princeton University Press, Princeton N.J., 1976, p. 156; reproduit al rocull de treballs del mateix autor, The Sea nd medieval Civilizations, Londres, 1978, estudi X.

${ }^{47}$ Sevillano ColOM, De Venecia a Flandes (cit. supra n. 38), p. 18 i A. RUDDOCK, Italian Merchants and Shipping in Southampton (1270-1600), Southampton, 1951, p. 21.

${ }^{48}$ LANE, Venetian merchant Galleys (cit. supran. 38), pp. 191-192.

${ }^{49}$ Ibidem, p. 192, i Giuseppe STEFANI, L'assicurazione a Venezia dalle origine alla fine della Serenissima. I., Trieste, 1956, p. 37.

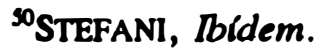


originats durant la primera gran època de la mudua veneciana, és a dir, entre 1317 i 1337.

Durant aquella epoca, hi ha documentades a Mallorca, el 1324, onze galeres venecianes, que hi feien escala anant a Flandes i, l'any 1332, hi ha documentada una altra d'aquestes mudue, de nou galeres venecianes, que feien escala a Mallorca tornant de Flandes ${ }^{51}$. No és, doncs, estrany que el mètode cronografic, del qual ens hem ocupat, arribés al coneixement de Cresques, que tenia l'ofici de cartograf. Aquest seu testimoniatge historic és, per ara, el més antic que coneixem del mètode de la rosa dels vents a la cronografia nàutica de la marea.

És per aixd que, com a apreciació conclusiva del conjunt d'observacions que acabem de fer, bé podem dir que, tant per la concordnça entre la metodologia nautica veneciana amb la de Cresques com per l'atenció singular que l'una i l'altra presten a les marees propies de les costes de la ruta comercial mediterrània de Flandes i Anglaterra, el metode cronogràfic de la rosa nàutica de la marea sembla haver-se originat en la navegació comercial d'aquesta ruta, la primera meitat del segle XIV.

La difusió posterior que tingué el dit metode sembla haver estat deguda a les obres clàssiques de l'Art de navegar renaixentista, tals com la de Pierre Garcie-Ferrande ${ }^{52}$, que hem citat al començament, o la de Pedro de Medina ${ }^{53}$, que hem fet servir aci també repetidament, les quals, durant el cinc-cents, tingueren edicions i traduccions diverses que en completaren l'efecte difusiu.

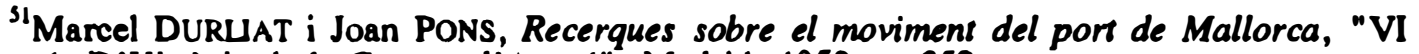
Congrés D'Història de la Corona d'Arag6", Madrid, 1959, p. 352.

${ }^{32}$ WATERS, The Rutters of the Sea, cit. supra n. 4, pp. 138 i 216, dels anys 1502 i 1521 , respectivament.

${ }^{33}$ Veg. supra n. 8.
} 


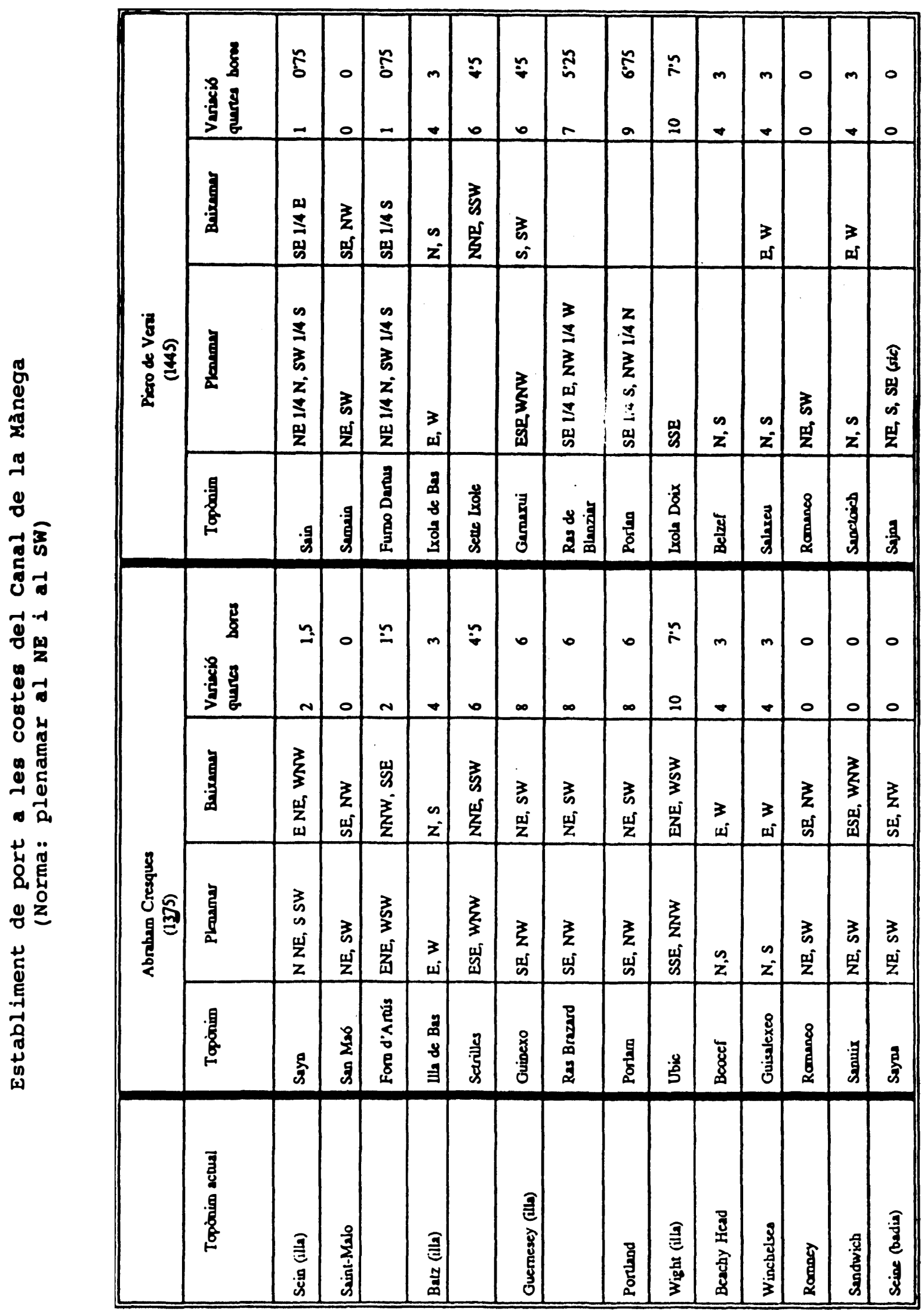




\section{RÉSUMÉ}

L'article étudie la difficulté que les navigateurs méditerranéens trouvèrent dans les marées quand ils arrivèrent aux rivages atlantiques aux dernières décades du XIIIle siècle et surtout pendant le XIVe siècle. Ils n'étaient pas acoutumés a ce phénomème naturel parce que il est presque inapreciable dans les côtes méditerranéennes. Ils furent donc obligés a connâ̂tre et apprendre le comput chronologique des marées, moyennant la rose des vents. L'article explique le fonctionnement de ce méthode et démontre qu'il fut découvert par les venitiens autour de 1317 et 1337 quand ils faisaient la route de Flandre.

\section{SUMMARY}

The article explains how difficult it was for the mediterranean sailors to solve the problem of the tides when they reached the Athlantic coasts in the last years of the XIIIth century and during the XIVth century. They were not used to this natural phenomenon because it is scarcely noticed in the Mediterranean Sea. So, they had to learn how to calculate the time by means of the traverse board. The article explains the management of this method and demonstrates that it was discovered by the Venetians between 1317 and 1337, when they began to navigate to Flanders. 